\title{
Bioresorbable Scaffolds
}

\author{
Sidakpal Panaich, Theodore Schreiber and Cindy Grines
}

Department of Cardiology, Detroit Medical Center, Michigan, US

\begin{abstract}
Percutaneous coronary intervention (PCI) has undergone major advances including the evolution in stent technology, from bare metal stents (BMS), to their drug eluting counterparts, to the development of bioresorbable scaffolds (BRS). The primary notion of BRS was to facilitate complete vascular healing and restore normal endothelial function following the resorption of stent scaffold while providing equivalent mechanical properties of a metallic drug eluting stents (DES) in the earlier stages. BRS provide attractive physiologic advancements over the existing DES and have shown promising results in initial clinical studies albeit with small sample sizes. Their use has been primarily restricted to patients recruited in clinical trials with limited real-world applicability. Thus, data from larger randomised control trials is awaited. The major objective of this article is to review the evidence on BRS and identify their clinical applicability in current interventional practice.
\end{abstract}

\section{Keywords}

Bioresorbable scaffolds, drug eluting stents, percutaneous coronary intervention

Disclosure: The authors have no conflicts of interest to declare.

Received: 1 July 2014 Accepted: 15 August 2014 Citation: Interventional Cardiology Review, 2014;9(3):175-9

Correspondence: Cindy Grines, Detroit Medical Center, Cardiovascular Institute, 311 Mack Ave, Detroit, MI 48201, US. E: cgrines@dmc.org

Percutaneous coronary intervention (PCl) is one of the most commonly performed procedures in cardiology. More recently, the limitations of rigid metallic stents have led to the development of bioresorbable scaffolds (BRS). The earliest version of bioresorbable stent developed and tested in humans in 1990 was the Igaki-Tamai stent. It featured a thermal and balloon expandable stent that showed good outcomes at six months ${ }^{1}$ as well as long-term² with neointimal hyperplasia similar to bare metal stents (BMS). The use of heat expansion, however, limited the clinical applicability of this device due to concerns of arterial wall necrosis with consequential platelet adhesion and stent thrombosis (ST). ${ }^{3}$ The development of new generation of BRS with improving mechanical performance is believed by some to be the next evolutionary leap in interventional cardiology. The major objective of this article is to review the evidence on BRS and identify their clinical applicability in current interventional practice.

\section{Problems With Metallic Stents and the Benefits of Bioresorbable Scaffolds}

In earlier days of balloon angioplasty, the adverse coronary vessel remodelling secondary to neointimal proliferation and extracellular matrix deposition as well as vessel recoil led to high restenosis rates. ${ }^{4,5}$ This early luminal loss was largely overcome by development of BMS that avoided vessel recoil and constrictive effects of vessel remodelling as well as any coronary flow impairment due to local dissections. ${ }^{6.7}$ However, the neointimal proliferative reaction to foreign body (metallic stent) resulted in greater intimal proliferation. ${ }^{8}$ The volume of neointimal proliferation was improved by introduction of drug eluting stents (DES) with anti-proliferative agents bound to stent polymers. ${ }^{9}$ Despite extensive literature on reduced revascularisation rates with DES, there have been multiple reports and safety concerns regarding occurrence of late and very late ST with DES..$^{10}$ It was thought to be due to delayed and at times incomplete endothelialisation.
This was a result of chronic inflammation from hypersensitivity reaction to the metallic stent and/or the durable polymers, which attenuates vascular healing.11-13 The presence of drug elution and a metallic stent are also believed to interfere with endothelial function. . $^{14,15}$ In addition, the persistent metallic scaffolding would subsequently limit expansive remodelling of the coronary artery. Loss of cyclic strain relief and protruding struts with resultant abnormal shear stress and strut fracture are other potential reasons for late cardiac events.

The primary notion of BRS was to facilitate complete vascular healing and restore normal endothelial function while providing equivalent mechanical properties of a metallic DES in the earlier stages (see Table 1). This was confirmed in recent imaging studies that demonstrated complete scaffold resorption and positive vessel remodelling. It was further accompanied by increase in luminal dimensions (plaque regression) and improved vasomotor function on drug (acetylcholine, nitroglycerin) testing. ${ }^{16}$ The incidence of late recurrence of residual anginal symptoms is high in patients who receive metallic DES; thus future trials are being designed to study the benefit of BRS in reducing residual angina symptoms. ${ }^{17}$

The complete disappearance of stent further appears attractive in plausibly eliminating the incidence of late and very-late ST. This could possibly shorten the duration of dual antiplatelet therapy (DAPT) and consequently reduce bleeding complications. The resorption of scaffolds would also plausibly avoid any hindrance from previous metal prosthesis during future interventions including placement of a bypass graft if needed in the future. Additionally, this could avoid problems associated with poorly aligned platforms or those blocking the side-branches. ${ }^{3}$ This is especially valuable in multivessel disease requiring multiple stent implantations. Indeed, $>100 \mathrm{~mm}$ of stent was implanted in the Synergy between PCI with taxus and cardiac surgery 
Table 1: Strengths and Weaknesses of Bioresorbable Scaffolds (BRS)

\begin{tabular}{l} 
Strengths \\
1. Restore normal vascular physiology including normal endothelial \\
function, vasomotion demonstrated on drug testing and return of \\
adaptive shear stress. \\
\hline 2. Late luminal enlargement demonstrated on various imaging studies. \\
Plaque Regression. \\
\hline 3. Potential reduction in late stent thrombosis and duration of dual \\
anti-platelet therapy. \\
\hline 4. Elimination of any permanent cage with no hindrance to future interventions \\
including bypass grafts. \\
\hline 5. Improved subsequent coronary imaging using multislice CT and MRI \\
without artifacts. \\
\hline 6. Alleviate any patient concerns regarding permanent metal implant in \\
their bodies. \\
\hline Weaknesses \\
1. Limited evidence in complex lesions like bifurcation lesions. \\
\hline 2. Thick scaffolds (>150 $\mu$ m) with limited expansion. \\
\hline 3. Difficult delivery in heavily calcified lesions due to high profile mandating \\
lesion preparation. \\
\hline 4. Accurate sizing of the stent requires imaging quantitative coronary \\
angiography (QCA). \\
\hline 5. High Cost. \\
\hline
\end{tabular}

(SYNTAX) trial in more than one-third of the enrolled patients. ${ }^{18}$ The DES are known to produce a "blooming artifact" on coronary computed tomography (CT) angiograms that could result in underestimation of intra-stent luminal diameter due to thickened appearance of the stent struts. 19,20 The BRS without any metal would thus afford the benefit of allowing better subsequent coronary imaging using multislice computerised tomography (CT) and magnetic resonance imaging (MRI) without artifacts. ${ }^{21}$ Furthermore, BRS can be intuitively thought of as drug reservoirs for local delivery due to their modifiable resorption rates. ${ }^{3}$ Lastly, bioresorbable stents would eradicate any patient concerns regarding permanent metal implant in their bodies. ${ }^{22}$

\section{Bioresorbable Scaffolds}

Table 2 shows the currently available BRS being tested in clinical trials. Poly L-lactic acid (PLLA) is the most commonly used material in BRS. PLLA is metabolised into carbon dioxide and water over a period of time (12-18 months), which is subsequently phagocytosed by the macrophages. ${ }^{23}$ ABSORB Bioabsorbable Vascular Scaffold (BVS) with a PLLA backbone releasing everolimus is the most widely investigated and the only approved bio-absorbable device (for de novo coronary lesions 2.0-3.8 mm in diameter). ${ }^{24}$ ABSORB Cohort A was an openlabel, prospective study of 30 patients with single de-novo lesions, which revealed acute recoil and late loss of scaffold area (-11.8\%) as measured by intravascular ultrasound (IVUS) (corresponding angiographic in-stent loss of $0.44 \mathrm{~mm}$ ) at six months. ${ }^{23} \mathrm{~A}$ follow-up study at two years using IVUS and optical coherence tomography (OCT) showed complete stent resorption, late luminal enlargement and absence of constrictive remodelling. ${ }^{25}$ Importantly, there was no incidence of ST at three years of follow-up and only one major adverse cardiac event (MACE) was reported at six months with no additional events at three years and five years of follow-up. ${ }^{26,27}$

Early recoil observed in the ABSORB study led to Revision 1.1 with modifications allowing for a longer duration of radial support. This iteration is believed to allow more uniform drug delivery along with superior vessel wall support due to better strut distribution..$^{28} \mathrm{~A}$ sixmonth analysis of this device in the ABSORB Cohort B trial showed encouraging results with late luminal loss of $0.19 \mathrm{~mm}$, which is comparable to many current generation DES. The MACE rate was noted to be $10 \%$ at three years without any scaffold thrombosis. In another substudy from cohort B trial, the circumferential neointimal tissue growth did not cause any luminal compromise between six months and two years using OCT.25

The results of the large-scale non-randomised, single-arm trial evaluating the second iteration of the ABSORB BVS (ABSORB EXTEND) in 1000 patients with longer lesions are expected in 2015. The preliminary results from 512 enrolled patients were noted to be promising with Iow ischaemia driven MACE and target vessel revascularisation (TVR) rates at $4.3 \%$ and $4.9 \%$ respectively at 12 months. ${ }^{29}$ In another randomised, single blind trial (ABSORB II), the ABSORB BVS will be tested against the everolimus DES, XIENCE. ${ }^{30}$ The ABSORB III trial is a non-inferiority trial $(n \sim 2,250)$ to evaluate one-year target lesion failure powered for non-inferiority against the XIENCE DES in subjects with up to two de novo native coronary artery lesions. In a second part of this trial (ABSORB IV), additional 3,000 patients would be recruited to study the primary end-point of patient reported angina at one-year and target lesion failure between 1-5 years. ${ }^{17}$ Results from separate randomised, non-inferiority trials comparing the safety and effectiveness of the ABSORB BVS in Japanese (ABSORB JAPAN) and Chinese (ABSORB CHINA) populations to the metallic XIENCE DES in ischaemic heart disease subjects are also awaited. ${ }^{11,32}$ Few clinical studies have evaluated the efficacy of ABSORB BVS in real-world practice. BVS were met with good in-hospital outcomes in the Polish absorb registry (POLAR) in patients with acute coronary syndrome (ACS) study with no mortality, myocardial infarction (MI) or ST reported in 88 patients enrolled. ${ }^{33}$ In another non-randomised study, patients presenting with acute coronary syndrome (ACS) underwent BVS ( $n=150)$ implantation and were compared with controls receiving DES ( $n=103)$. Thirty-day and six-month MACE rates were noted to be similar between the two groups. ${ }^{34}$ BVS also showed promise with similar clinical outcomes as patients receiving DES in the PRAGUE-19 registry when used for primary $\mathrm{PCl}$ in ST elevation myocardial infarction (STEMI) other than calcified and tortuous lesions..$^{35}$ The results of an ongoing randomised trial (ABSORB STEMI: TROFI II study) designed to compare the neointimal healing score at six months in STEMI patients treated with ABSORB BVS and XIENCE DES are awaited. ${ }^{36}$

The first Poly (iodinated desaminotyrosyl-tyrosine ethyl ester) carbonate stent or REVA stent was met with high rate of target vessel revascularisation (TLR) secondary to mechanical failures. ${ }^{37}$ A redesigned version (Rezolve) with a more robust polymer with a sheathed delivery system (limiting its use in smaller vessels) was developed, which was again modified into Rezolve2 with a lower profile and sheathless delivery system being evaluated in the ongoing pilot study of the ReZolve ${ }^{\mathrm{TM}}$ airolimus-eluting bioresorbable coronary stent (RESTORE) trial. ${ }^{38}$

Although safety and radial strength of another bioresorbable stent, the IDEAL Poly (anhydride ester) salicylic acid stent ${ }^{39}$ were demonstrated in a 12-month follow up of a small $(n=11)$ number of patients, the neointimal suppression was deemed to be insufficient due to low dose and rapid elution of sirolimus. ${ }^{40} \mathrm{~A}$ revised version with higher dose of sirolimus and optimised stent design with thinner struts is undergoing pre-clinical trials. 
Table 2: Bioresorbable Stents Being Currently Tested in Clinical Trials

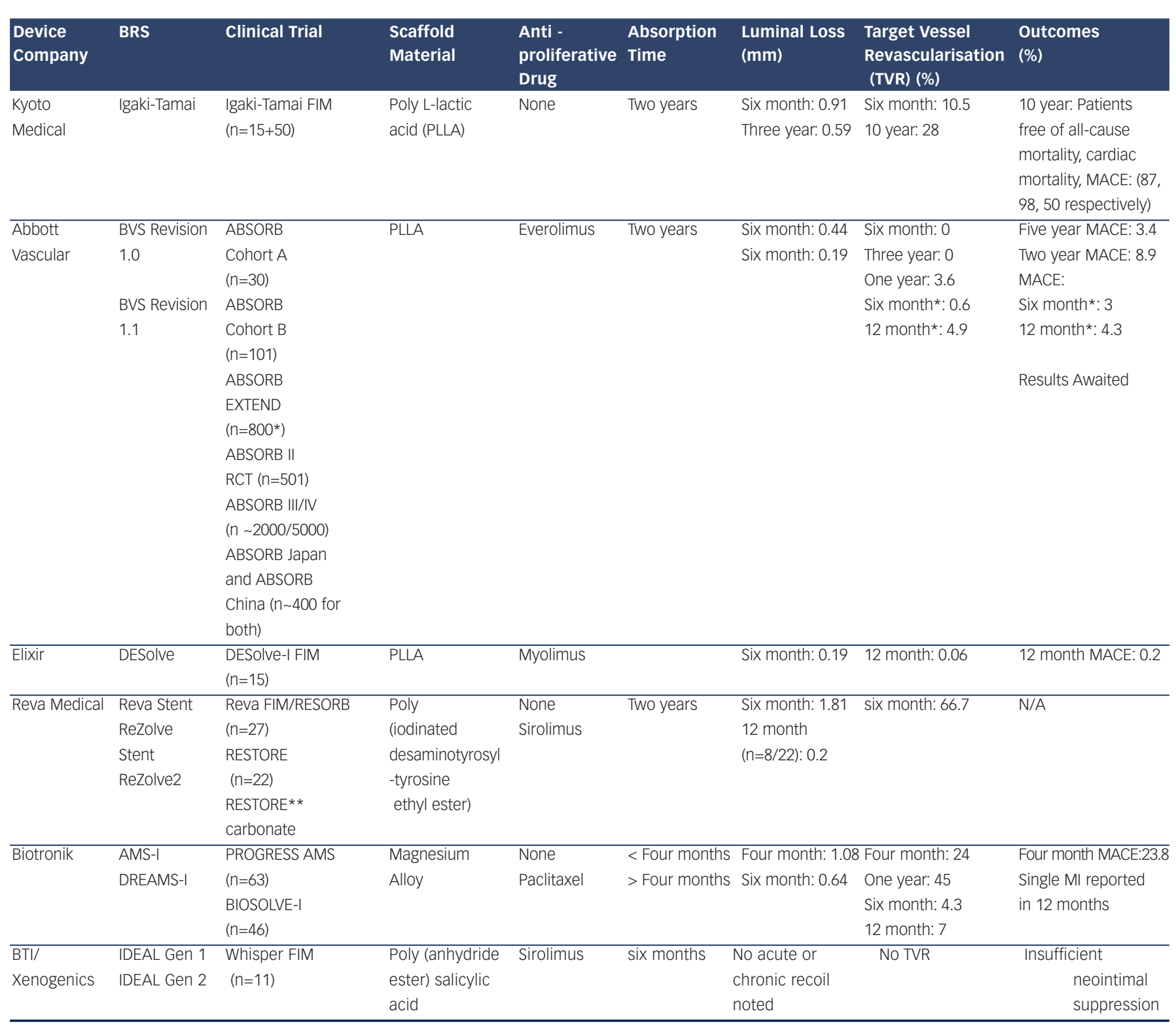

*Ongoing Trial with projected sample size; preliminary data presented from 512 patients. **Ongoing trial designed to include modification of the Rezolve stent with sheathless delivery; $M A C E=$ major adverse cardiovascular events; TVR = Target vessel revascularization; FIM = First in-man; BRS = Bioresorbable Scaffold; BVS = Bioabsorbable Vascular Scaffold. Adapted from Garg and Serruys. ${ }^{38}$

The initial iterations of non-drug eluting magnesium based absorbable scaffolds were met with disappointing results. The TVR rates were $39.7 \%$ at four months and $45 \%$ at 12 months due to both neointimal hyperplasia and recoil in the Clinical performance angiographic results of coronary stenting with absorbable metal stents (PROGRESS) AMS study. ${ }^{41}$ BIOSOLVE-I was the in-man trial to evaluate the efficacy of first paclitaxel-eluting absorbable magnesium based metal scaffold drug-eluting absorbable metal scaffold (DREAMS). It demonstrated similar TVR rates as contemporary DES and everolimus-eluting BRS though it did not match the late lumen results noted with either platform. ${ }^{42}$

\section{The Pitfalls and Challenges}

Most of the existing literature on BRS is limited to their utility in simple Type A lesions. The interventionalists thus remain skeptical regarding their applicability in complex lesions more commonly encountered in real world practice. The delivery of BRS in calcified and complex lesions is relatively difficult given the stent size and strut thickness. A recent study reported higher strut malapposition with BRS used in fibrocalcific plaques. ${ }^{43}$ Additionally, the relatively lower radial strength of BRS could plausibly limit their expansion in heavily calcified lesions. Given the high profile of these scaffolds, adequate lesion preparation with rotablation or noncompliant scoring balloons might be obligatory to expand their use in complex lesions per some authors. ${ }^{44}$ Indeed, the limited expansion of BRS precludes aggressive post-dilation, which makes adequate lesion preparation and vessel sizing imperative. Improved BRS expansion has been previously noted following 1:1 balloon:vessel pre-dilation. ${ }^{43}$ The restricted distensibility of everolimus-eluting BRS may require IVUS, OCT or quantitative coronary angiography (QCA) for precise measurement of maximal distal and proximal coronary luminal reference diameters (Dmax) to accurately size the stent and thus avoid over or undersizing of the device with subsequent incomplete strut apposition..$^{24,45}$

The chronic scaffold recoil noted with ABSORB Version 1.0 in Cohort A trial occurs secondary to loss of radial strength during resorption 
and is not observed with non-absorbable DES. Likewise, the in-vivo resorption of the scaffold and its mechanical strength do not have a linear relationship. ${ }^{38}$ This might make the decline in device's mechanical performance with minimal resorption or changes in stent mass unpredictable. Conversely, the DREAMS magnesium based scaffold showed better conformability with superior strut apposition in the BIOSOLVE-I trial though with other limitations noted above. ${ }^{42}$ The other notable limitation of polymer (PLLA) based BRS is the lack of radio-opacity, which obligates the use of radioopaque markers.

\section{Special Populations and Future Directions}

Besides long calcified lesions, data is also sparse for use of BRS in treatment of in-stent restenosis (ISR). The BRS might prove attractive for ISR and avoid multiple metallic layers of scaffolds and polymers in a coronary artery thereby plausibly reducing chronic inflammation and neointimal hyperplasia. ${ }^{46}$ Likewise, clinical studies have neither included bifurcation lesions with side branches $\geq 2 \mathrm{~mm}$ in diameter, evaluated the "kissing balloon" technique nor is there sufficient data to recommend the use of BRS in chronic total occlusions or coronary artery bypass grafts. ${ }^{24}$

Furthermore, BRS will need critical analysis in various higher risk subgroups including diabetics, elderly as well as individuals presenting with ACS in larger sample size studies with longer prospective followups. In a propensity match analysis of ABSORB BRS (from Cohort B and Extend Trials) and everolimus DES (from SPIRIT trials), no significant difference in outcomes was noted amongst diabetic patients treated with either platform. ${ }^{47}$

The pace of scaffold resorption can vary depending on the PLLA manufacturing process. Thus, every device needs to be tested appropriately for in-vivo biocompatibility. This is important since previously published literature has demonstrated the influence of scaffold's molecular weight on the degree of inflammation, ${ }^{48}$ which could further influence the neointimal response. Additionally, with varying absorption times, the ideal resorption duration of scaffolding remains to be elucidated. On the basis of previously published IVUS study that showed negative vascular remodelling for up to six months ${ }^{8}$ an ideal scaffold should provide protection against negative remodelling for at least six months though this merits further confirmation.

The current generation of DES has demonstrated improved outcomes with especially reduced rates of both late and very late ST. ${ }^{49}$ Indeed, emerging literature involving recent post-hoc analysis of pooled data from major trials demonstrated no adverse thrombotic events after earlier discontinuation of DAPT. This poses several questions for emerging technology as BRS including feasibility of designing adequately powered trials to prove the superiority of BRS over currently available DES..$^{50}$ Whether BRS would further reduce DAPT requirements, lower stent fracture complications and even improve coronary vasomotor function over long term remains to be demonstrated in larger clinical and in-vivo physiological studies. Future pre-clinical studies focused on extensively studying pathophysiological underpinnings of BRS mechanisms are imperative. Furthermore, the real clinical implications of vasomotor restoration phenomenon would need further evaluation.

Of note, the various physiological benefits of BRS are not expected until late (likely after first year) and thus longer follow-ups would be needed to elucidate favourable contributions over their metallic counterparts. Indeed, in a recent serial tomographic evaluation of BRS form ABSORB Cohort B, the in-scaffold loss was noted to be stable after one year in contradistinction to everolimus stent from SPIRIT II trial (increase from $0.17 \mathrm{~mm}$ at six months to $0.33 \mathrm{~mm}$ at years years). ${ }^{11,52}$ This was accompanied by significant luminal enlargement between one and three years $\left(6.35 \mathrm{~mm}^{2}\right.$ at one year and $6.81 \mathrm{~mm}^{2}$ at three years, $\mathrm{p}<$ $0.001)$ in case of BRS. ${ }^{16}$

\section{Conclusion}

BRS offer an attractive theoretical advantage in absolution of late and very-late stent thrombosis. Despite promising clinical outcomes compared to existing DES, their use has been primarily restricted to patients recruited in clinical trials with strict eligibility criteria. Larger comparative trials with critical safety and efficacy analysis of newer BRS with improving designs and biomechanical properties are nearing completion. We eagerly await these results before the widespread use of BRS can be recommended, especially considering improving technology and outcomes with third generation metallic DES.
1. Tamai H, Igaki K, Kyo E, et al. Initial and six-month results of biodegradable poly--l-lactic acid coronary stents in humans. biodegradable poly-I-lactic acid coron
circulation 2000 Jul 25:102(4):399-404.

2. Nishio S, Kosuga K, Igaki K, et al. Long-Term (>10 Years) clinical outcomes of first-in-human biodegradable poly-llactic acid coronary stents: Igaki-Tamai stents. Circulation 2012 May 15;125:2343-53.

3. Onuma Y, Serruys PW. Bioresorbable scaffold: the advent of a new era in percutaneous coronary and peripheral revascularization? Circulation $2011 \mathrm{Feb} 22 ; 123: 779-97$.

4. Sigwart U, Puel J, Mirkovitch V, et al. Intravascular stents to prevent occlusion and restenosis after transluminal angioplasty. N Eng/ J Med 1987 Mar 19;316:701-6.

5. Nobuyoshi M, Kimura T, Nosaka $H$, et al. Restenosis after successful percutaneous transluminal coronary angioplasty: serial angiographic follow-up of 229 patients. J Am Coll Cardio 1988 sep;12:616-23.

6. Luo H, Nishioka T, Eigler NL, et al. Coronary artery restenosis after balloon angioplasty in humans is associated with circumferential coronary constriction. Arterioscler Thromb Vas Biol 1996 Nov; 16:1393-8.

7. Fischman DL, Leon MB, Baim DS, et al. A randomized comparison of coronary-stent placement and balloon angioplasty in the treatment of coronary artery disease. Stent Restenosis Study Investigators. N Eng/ I Med 1994 Aug 25;331:496-501.

8. Hoffmann R, Mintz GS, Dussaillant GR, et al. Patterns and mechanisms of in-stent restenosis. A serial intravascular ultrasound study. Circulation 1996 Sep 15:94:1247-54.

9. Sousa JE, Costa MA, Abizaid A, et al. s-coated stents in human coronary arteries: a quantitative coronary angiography and three-dimensional intravascular ultrasound study Circulation 2001 Jan 16:103:192-5.

10. Stettler C, Wandel S, Allemann S, et al. Outcomes associated with drug-eluting and bare-metal stents: a collaborative network meta-analysis. Lancet 2007 Sep 15;370:937-48.

11. Joner M, Finn AV, Farb A, et al. Pathology of drug-eluting stents in humans: delayed healing and late thrombotic risk. J Am Coll Cardiol 2006 Jul 4;48:193-202.

12. Stefanini GG, Kalesan B, Serruys PW, et al. Long-term clinical outcomes of biodegradable polymer biolimus-eluting stents versus durable polymer sirolimus-eluting stents in patients with coronary artery disease (LEADERS): 4 year followup of a randomised non-inferiority trial. Lancet 2011 Dec 3;378:1940-8.

13. Wenaweser P, Daemen J, Zwahlen M, et al. Incidence and correlates of drug-eluting stent thrombosis in routine clinica practice. 4-year results from a large 2-institutional cohort study. J Am Coll Cardiol 2008 Sep 30;52:1134-40.

14. Togni M, Windecker S, Cocchia R, et al. Sirolimus-eluting stents associated with paradoxic coronary vasoconstriction. J Am Coll Cardiol 2005 Jul 19;46:231-6.

15. Hofma SH, van der Giessen WJ, van Dalen BM, et al. Indication of long-term endothelial dysfunction after sirolimus-eluting stent implantation. Eur Heart J 2006 Jan;27:166-70.

16. Serruys PW, Onuma Y, Dudek D, et al. Evaluation of the second generation of a bioresorbable everolimus-eluting vascular scaffold for the treatment of de novo coronary artery stenosis: 12-month clinical and imaging outcomes. I Am Coll Cardiol 2011 Oct 4;58:1578-88.

17. ABSORB III Randomized Controlled Trial (RCT) (ABSORB-III) Abbott Vascular; [cited 2014 Jun 23]; Available from: http:// www.clinicaltrials.gov/show/NCT01751906.

18. Serruys PW, Morice MC, Kappetein AP, et al. Percutaneous coronary intervention versus coronary-artery bypass graftin for severe coronary artery disease. N Eng/ I Med 2009 Mar 5;360:961-72

Mahnken AH. CT Imaging of Coronary Stents: Past, Present, and Future ISRN Cardiol 2012:2012:139823.

20. Spuentrup E, Ruebben A, Mahnken A, et al. Artifact-free coronary magnetic resonance angiography and coronary vessel wall imaging in the presence of a new, metallic, coronary magnetic resonance imaging stent. Circulation 2005 Mar 1;111:1019-26

21. Erbel R, Bose D, Haude M, et al. [Absorbable coronary stents. New promising technology]. Herz2007 Jun;32:308-19.

22. Ormiston JA, Serruys PW. Bioabsorbable coronary stents. Circ Cardiovasc Interv 2009 Jun;2:255-60.

23. Ormiston JA, Serruys PW, Regar E, et al. A bioabsorbable everolimus-eluting coronary stent system for patients with single de-novo coronary artery lesions (ABSORB): a prospective open-label trial. Lancet 2008 Mar 15;371:899-907.

24. Rzeszutko L, Depukat R, Dudek D. Biodegradable vascular scaffold ABSORB BVS - scientific evidence and methods of implantation. Postepy Kardiol Interwencyinej 2013;9:22-30.

25. Serruys PW, Ormiston JA, Onuma Y, et al. A bioabsorbable everolimus-eluting coronary stent system (ABSORB): 2-year outcomes and results from multiple imaging methods. Lancet 2009 Mar 14;373:897-910

26. Onuma Y, Serruys PW, Ormiston JA, et al. Three-year results of clinical follow-up after a bioresorbable everolimus-eluting scaffold in patients with de novo coronary artery disease: the ABSORB trial. Eurolntervention 2010 Sep;6:447-53.

27. Onuma $Y$, Dudek D, Thuesen L, et al. Five-year clinical and functional multislice computed tomography angiographic results after coronary implantation of the fully resorbable 
polymeric everolimus-eluting scaffold in patients with de novo coronary artery disease: the ABSORB cohort A trial. IACC Cardiovasc Interv 2013 Oct:6:999-1009.

28. Okamura T, Garg S, Gutierrez-Chico JL, et al. In vivo evaluation of stent strut distribution patterns in the bioabsorbable everolimus-eluting device: an OCT ad hoc analysis of the revision 1.0 and revision 1.1 stent design in the ABSORB clinical trial. Eurolnterv

29. Abizaid A, Costa JR, Jr., Bartorelli AL, et al. The ABSORB EXTEND study: preliminary report of the twelve-month clinical outcomes in the first 512 patients enrolled. Eurolntervention 2014 Apr 29

30. Diletti R, Serruys PW, Farooq V, et al. ABSORB II randomized controlled trial: a clinical evaluation to compare the safety, efficacy, and performance of the Absorb everolimus-eluting bioresorbable vascular scaffold system against the XIENCE everolimus-eluting coronary stent system in the treatment of subjects with ischemic heart disease caused by de novo native coronary artery lesions: rationale and study design. Am Heart J 2012 Nov; 164:654-63.

31. A Clinical Evaluation of Absorb ${ }^{\top M}$ Bioresorbable Vascular Scaffold (AbsorbTM BVS) System in Chinese Population ABSORB CHINA RCT. Abbott Vascular; [cited 2014 Jun 23]; Available from: http://www.clinicaltrials.gov/ct2/show/ NCT01923740.

32. AVJ-301 Clinical Trial: A Clinical Evaluation of AVJ-301 (AbsorbTM BVS) in Japanese Population (ABSORB JAPAN) Abbott Vascular; [cited 2014 Jun 23]; Available from: http://clinicaltrials.gov/show/NCT01844284.

33. Dudek D, editor POLAR ACS: bio-absorbable platform in acute coronary syndromes. euroPCR; 2013; Paris, France. simsek C, Magro M, Onuma Y, et al. Procedural and clinical outcomes of the Absorb everolimus-eluting bioresorbable vascular scaffold. one-month results of the Bioresorbable vascular Scaffold Evaluated At Rotterdam Cardiology Hospitals (B-SEARCH). Eurolntervention 2013 Sep 4.

35. Kocka V Maly M, Tousek P, et al. Bioresorbable vascula scaffolds in acute ST-segment elevation myocardial infarction: a prospective multicentre study 'Prague 19'. Her Heart I 2014 Mar:35:787-794.

36. ABSORB STEMI: the TROFI II Study. ECRI bv; [cited 2014 Jun 23]; Available from: http://clinicaltrials.gov/show/ NCT01986803.

37. Pollman MJ. Engineering a bioresorbable stent: REVA programme update. Eurolntervention 2009 Dec 15;5 Suppl F:F54-7.

38. Garg S, Serruys PW. Coronary stents: looking forward. J Am Coll Cardiol 2010 Aug 31;56(10 Suppl):S43-78.

39. Jabara R, Pendyala L, Geva S, et al. Novel fully bioabsorbable salicylate-based sirolimus-eluting stent. Eurolntervention 2009 Dec 15;5 Suppl F:F58-64.

40. Jabara R. Poly-anhydride based on salicylic acid and adipic acid anhydride. EuroPCR; 2009

Temporary scaffolding of coronary arteries with bioabsorbable magnesium stents: a prospective, non-randomised multicentre trial. Lancet 2007 Jun 2;369:1869-75

42. Haude M, Erbel R, Erne P, et al. Safety and performance of the drug-eluting absorbable metal scaffold (DREAMS) in patients with de-novo coronary lesions: 12 month results of the prospective, multicentre, first-in-man BIOSOLVE-I trial. Lancet 2013 Mar 9;381:836-44

43. Brown AJ, McCormick LM, Braganza DM, et al. Expansion and malapposition characteristics after bioresorbable vascular scaffold implantation. Catheter Cardiovasc Interv 2014 Jul 1;84:37-45.

44. Basavarajaiah S, Naganuma T, Latib A, Colombo A. Can bioabsorbable scaffolds be used in calcified lesions? Catheter Cardiovasc Interv 2013 Apr 16.
45. Gomez-Lara J, Diletti R, Brugaletta S, et al. Angiographic maximal luminal diameter and appropriate deployment of the everolimus-eluting bioresorbable vascular scaffold as assessed by optical coherence tomography: an ABSORB cohort B trial sub-study. Eurolntervention 2012 Jun 20;8:214-24.

46. Ielasi A, Latib A, Naganuma T, et al. Early results following everolimus-eluting bioresorbable vascular scaffold implantation for the treatment of in-stent restenosis. Int J Cardiol 2014 May 15;173:513-4.

7. Muramatsu T, Onuma Y, van Geuns RJ, et al. One-Year Clinical Outcomes of Diabetic Patients Treated With Everolimus-Eluting Bioresorbable Vascular Scaffolds: A Pooled Analysis of the ABSORB and the SPIRIT Trials. JACC Cardiovasc Interv 2014 Apr 10

48. Lincoff AM, Furst JG, Ellis SG, et al. Sustained local delivery of dexamethasone by a novel intravascular eluting stent to prevent restenosis in the porcine coronary injury model. J Am Coll Cardiol 1997 Mar 15;29(4):808-16.

49. Palmerini T, Biondi-Zoccai G, Della Riva D, et al. Stent thrombosis with drug-eluting and bare-metal stents: evidence from a comprehensive network meta-analysis. Lancet 2012 Apr 14;379:1393-402.

50. Dauerman HL. The magic of disappearing stents. I Am Coll Cardiol 2011 Oct 4;58:1589-91.

51. Claessen BE, Bejik MA, Legrand V, et al. Two-year clinical, angiographic, and intravascular ultrasound follow-up of the XIENCE V everolimus-eluting stent in the treatment of patients with de novo native coronary artery lesions: the SPIRIT II trial. Circ Cardiovasc Interv 2009 Aug;2:339-47.

52. Ormiston JA, Serruys PW, Onuma Y, et al. First serial assessment at 6 months and 2 years of the second generation of absorb everolimus-eluting bioresorbable vascular scaffold: a multi-imaging modality study. circ Cardiovasc Interv 2012 Oct; 5:620-32. 